\title{
Programa de integridade: ação, compromisso e transparência
}

\section{Integrity program: action, commitment and transparency}

\section{Programa de integridad: acción, compromiso y transparencia}

\section{Eduardo Staino'}

\footnotetext{
modelo de fazer negócios no país, principalmente aquele estabelecido com instituições do Poder Executivo, entrou em colapso. A operação Lava Jato expôs as práticas nocivas, o famoso jeitinho, o "levar vantagem em tudo" que funcionou por muitas décadas no Brasil.
}

O assunto não se restringe ao Governo. Com a lupa apontada para corporações de grande porte, operações da Polícia Federal sugerem que a prática da corrupção no mundo empresarial tem sido cada vez menos tolerada no país.

É importante dizer que, até pouco antes de 2014, muitas pessoas e empresas no Brasil não sabiam como escrever a palavra compliance. Todavia, com as mudanças setoriais e empresariais, essas mesmas companhias têm se reinventado, por meio da bandeira da integridade e ética. Esse movimento somente pode ser feito com mudança de aspectos culturais internos e externos às organizações, visto que empresas nada mais são que um conjunto de pessoas com um objetivo comum. Dessa forma, o pilar da integridade é tocar e mudar radicalmente a cultura da sociedade.

Tendo em vista esse cenário, a Andrade Gutierrez (AG) tem investido em um robusto programa de integridade, de modo a deixar as práticas não-republicanas definitivamente no passado.

De maneira convicta, o Programa de Compliance e Integridade da AG começou a ser implantado em 2013, em linha com as melhores práticas adotadas em todo o mundo. Essa iniciativa antecipada, isto é, desatrelada a um evento bastante negativo, tem sido muito importante para que a $A G$ já possa se beneficiar dessa decisão.

1 Diretor de Compliance da Andrade Gutierrez. Mestre em Finanças, Controladoria e Auditoria pela Fundação Getúlio Vargas (FGV). E-mail: Eduardo.staino@agnet.com.br. 
A AG entende que compliance e integridade são um conjunto de práticas e comportamentos que objetivam manter a empresa aderente às leis e às suas normas e procedimentos, estabelecendo uma conduta ética em todas as suas esferas de atuação, de modo a fortalecer sua governança, integridade, competência, eficiência e competitividade, e a preservar sua sustentabilidade e perenidade.

O programa tem como base o compromisso da liderança, ações de treinamento e a comunicação com seus públicos de interesse. Além disso, está estruturado em dois eixos: prevenção e monitoramento.

As ações de prevenção procuram estabelecer mecanismos preventivos à materialização de riscos empresariais e de compliance, incluindo o Código de ética e de conduta, políticas, normas e procedimentos, controles internos e avaliação de terceiros. Já as ações de monitoramento têm por objetivo avaliar e verificar se todas as definições do programa estão sendo adequadamente cumpridas, e detectar possíveis falhas dos processos ou descumprimentos das políticas.

Para a estruturação, monitoramento e aprimoramento do programa, a AG possui uma equipe executiva dedicada ao desenvolvimento de suas atividades. A equipe de Compliance, com status de diretoria, reporta-se exclusivamente à alta liderança da companhia, para garantir sua independência, autonomia e efetividade.

O programa está baseado na análise de perfil da companhia, incluindo setores de mercado, estrutura organizacional, riscos inerentes à sua operação e negócios e integração com o poder público.

Todo o programa é concebido a partir dos pilares "compromisso da liderança" e "treinamento e comunicação". O primeiro pilar atribui a relação de patrocínio, compromisso, empenho e determinação da liderança da companhia em todas as iniciativas do programa. 0 segundo agrupa um conjunto de ações que visam a treinar, comunicar, conscientizar e debater a cultura de ética, transparência e cumprimento da legislação vigente.

No decorrer do ano de 2014, a linhada com sua nova estrutura de governança, a AG lançou seu novo Código de ética e conduta para todo o público. Foi enviado um comunicado corporativo para todos os funcionários da AG e, com o objetivo de salientar o compromisso da alta administração com o código, o presidente da companhia gravou um vídeo convidando todos os colaboradores a conhecer o documento, de aplicação obrigatória a todos.

Além de receber uma cópia eletrônica, cada colaborador da AG ganhou um exemplar físico do documento, sendo obrigatória a assinatura do termo de compromisso, no qual se obriga a conhecer e aplicar as diretrizes nele presentes. 0 lançamento do novo Código de ética e conduta foi amplamente abordado nos veículos de comunicação da AG. Para facilitar sua compreensão, foi criado e divulgado um documento de apoio com perguntas e respostas, sanando as principais dúvidas do público-alvo.

O lançamento foi conduzido pela alta administração da AG, sendo realizados oito eventos presenciais (workshops e palestras) para a disseminação do código, da legislação vigente e do programa de integridade. Colaboradores de todas as unidades se encontraram em cidades como Rio de Janeiro, São Paulo, Belo Horizonte, Lisboa e Lima para participar dos eventos, assistir as apresentações e debater o tema.

Além da condução de treinamentos, as ações do programa são cuidadosamente acompanhadas pelo Comitê de Ética e Conselho de Administração da AG. Mensalmente, a equipe de Compliance é responsável por apresentar as atividades e ações desempenhadas e o planejamento de ações futuras. 
Ainda em 2014, foi criado um canal confidencial para recebimento de reclamações e denúncias - que inclusive foi terceirizado, de maneira a operar com a máxima força e total independência. Nos últimos 12 meses, foram feitas mais de 250 denúncias, e já ocorreram desligamentos em razão de comportamentos inaceitáveis.

O planejamento estratégico da AG foi reformulado, e as diretrizes de compliancee ética foram incorporadas aos direcionadores estratégicos da empresa. Os executivos da companhia passaram a ter metas formais para cumprir as etapas das ações de compliance, e esses indicadores são constantemente avaliados e discutidos para medir o desempenho individual. 0 compromisso absoluto é com a ética e a correção, sem espaço para quaisquer desvios.

O plano vai muito além de regras explícitas, e está atrelado ao comportamento de todos os colaboradores da empresa, independentemente de níveis hierárquicos. Ou seja, tudo aquilo que não for ético, mesmo não estando sob a avaliação de uma regra escrita, deve ser imediata e fortemente rechaçado.

Além de toda a estrutura dedicada a compliance e integridade, a atuação do programa foi ampliada, por meio da definição de "agentes de compliance". Os agentes são colaboradores de diversas áreas de negócio da AG que, além de suas atividades ordinárias, desempenham a função de multiplicar o programa, prezar pela manutenção da cultura de ética, integridade e transparência.

A partir da definição de perfil do agente de compliance, os gestores das unidades (obras, escritórios etc.) foram convidados a indicar colaboradores que se enquadravam nos objetivos de sua atuação. Os colaboradores indicados foram submetidos a um processo de validação, levando em conta o histórico na organização, habilidades de comunicação e boa reputação. Com isso, foram convidados mais de 100 agentes de compliance em todos os locais onde a AG atua.

Em 2015, ocorreu $01^{0}$ Encontro dos Agentes de Compliance do Brasil. Durante esse evento, os agentes tiveram a oportunidade de conhecer todo o programa de compliance e integridade, debater seus principais itens e propor ações concretas. Adicionalmente, foram explicados o papel de um agente de compliance es mecanismos de desdobramentos nas unidades. 0 evento contou com a presença da Presidência, da Vice-Presidência Financeira e da Superintendência Jurídica da AG.

Em 2016, como um aprimoramento do Programa de Compliance e Integridade, foi aplicado o conceito de "meta de compliance penalizadora". Na prática, significa dizer que, caso um colaborador descumpra alguma diretriz do Código de ética e conduta, seu indicador de performance anual é diminuído. Em determinadas situações, o indicador pode ser levado a zero.

Recentemente, foi lançado o Book de políticas da Andrade Gutierrez Engenharia, um conjunto de diretrizes formado pelas políticas de Governança Empresarial, Desenvolvimento de Negócios, Gerenciamento de Execução dos Contratos, Gestão de Gente, Aquisição e Gestão de Ativos, Materiais e Serviços, e Finanças e Controladoria.

A partir dessas políticas, normas e procedimentos são desdobrados, para garantir uma gestão empresarial simples, eficaz e adequada aos objetivos da AG. São exemplos a Política de Governança Empresarial, a Norma de Gestão de Fornecedores, e o Procedimento de Gestão de Ocorrências Socioambientais.

Além do já mencionado Código de ética e conduta, a AG, buscando uma resposta específica às situações com maior grau de especialidade, desenvolveu também outros documentos internos relacionados ao Programa de Compliance e Integridade. A companhia também elaborou a Política de Relacionamento com o Poder Público, e definiu um novo processo de avaliação de fornecedores, além de uma série de treinamentos visando ao aprimoramento da cultura de transparência e integridade. 
No pedido de desculpas da $A G$ à nação, um manifesto publicado em maio do ano passado nos principais jornais do país, uma das muitas propostas é, justamente, que o modelo de governança em empresas estatais e órgãos públicos garanta que decisões técnicas sejam tomadas por profissionais concursados e sem filiação partidária. Dessa forma, se estabelece uma nova relação entre prestadores de serviços e o setor público, criando um ambiente de negócios mais sadio e transparente entre as partes, tendo a sociedade como principal beneficiada. 0 comportamento de transparência da AG e seu comprometimento com o acordo de leniência firmado demonstram sua clara "virada de página".

Hoje, a decisão pela entrada de qualquer novo negócio na AG é tomada, obrigatoriamente, após a avaliação de uma série de aspectos. Um deles é a análise do cliente/mercado. Somente após as avaliações de compliance e a certificação de que 0 novo negócio é aderente às regras da $A G$ é que a negociação avança.

No Book de políticas da Andrade Gutierrez Engenhariaainda estão contempladas a Norma de Relacionamento com Fornecedores - documento que define a conduta ética esperada por colaboradores da AG em processos de aquisição de bens, materiais e serviços; a Norma de Segurança da Informação - documento que estabelece as regras de segurança da informação adotadas pela AG e pautadas por princípios éticos e legais; a Norma de Gestão do Caixa - documento que orienta e estabelece diretrizes corporativas inerentes ao processo de gestão de caixa da AG; a Norma de Política de Aquisiç̧ão e Gestão de Ativos, Materiais e Serviços - documento que define diretrizes, orientações e regras gerais para o processo de aquisição e gestão de ativos, materiais e serviços; a Norma de Gestão de Contratos de Subempreitada -com a finalidade de estabelecer regras a serem observadas para contratação e gestão de serviços de subempreiteiro/prestador de serviço; e, por último, a Norma de Participação em Entidades Representativas - documento que tem como objetivo regulamentar os parâmetros de participação da $A G$ em entidades representativas, como associações, federações, confederações, sindicatos e entidades de classe, bem como das contribuições a elas.

Importante enfatizar que a AG também faz um monitoramento estreito dos requisitos legais aplicáveis a cada uma de suas unidades (obras e escritórios). No momento em que uma nova unidade se inicia, são contratadas empresas especializadas e/ou um escritório de advocacia no mapeamento dos requisitos legais, de acordo com o escopo de atividade, principalmente no que tange às legislações ambiental, de saúde ocupacional, de segurança do trabalho e de responsabilidade social. Todo o mapeamento é registrado em sistema informatizado, e os requisitos legais são devidamente geridos com o objetivo de mitigar riscos. A gestão dos requisitos legais dá origem aos indicadores de conformidade legais, que mensuram quão aderente as unidades estão em relação à legislação. 0 resultado apurado nos indicadores é registrado no painel de acompanhamento geral da unidade.

Todas essas medidas foram comunicadas para os diferentes públicos-alvo da companhia, a fim de amplificar a divulgação do conteúdo do Programa de Compliance e Integridade para todos os colaboradores da empresa no Brasil e no mundo, além de clientes, fornecedores e parceiros.

Como dito, a AG incorporou diferentes iniciativas para monitorar a lisura e a transparência de suas relações comerciais, seja com clientes ou fornecedores. Se consideramos que uma empresa vive de seus negócios na sociedade, temos também fomentado esse tema com o restante de nossa cadeia de valor. 0 objetivo é que nossos fornecedores, clientes e o mercado em geral sejam cativados pela cultura de integridade que o Brasil começa (para alguns, a passos largos; para outros, a passos de tartaruga) a implantar. As empresas deverão se preocupar com sua competitividade, eficiência e eficácia para ganhar negócios.

Porém, por mais avançada que a AG esteja nesse trabalho, é importante ter em mente que refletir sobre comportamento ético e adotar práticas alinhadas com o compliance são ações contínuas, que devem ser exercidas todos os dias. Continuaremos nessa incessante busca. 
Nosso Programa de Compliance e Integridade tem recebido diversos reconhecimentos nacionais e internacionais. E queremos mais. Queremos ser reconhecidos como uma empresa com engenharia de ponta, de excelência operacional e que ganha contratos e projetos para melhorar o Brasil e todos os países em que atua. Esse é o nosso lema.

Depoimento recebido em 13.11.2017 e aceito em 19.12.2017. 